\title{
The Paradox of Gustatory Taste
}

\author{
HEIDI FUREY
}

\begin{abstract}
In this paper I introduce and solve a puzzle that arises at the intersection of aesthetics and linguistics: the "Paradox of Gustatory Taste." The puzzle essentially involves explaining how taste disagreements can be both subjective and objective-a seemingly paradoxical task. The puzzle has its roots in linguistically based observations about taste disagreements, and has important implications not only for aesthetics but for philosophy of language as well. I claim the paradox can be resolved, without reference to a semantic theory, by appealing to a theory of gustatory value. To demonstrate this point, I develop such a theory, which I model on a Humean approach to aesthetic value presented by Peter Railton. I argue this theory can fully resolve the paradox of taste and has the benefit of remaining neutral with regard to the semantics of predicates of personal taste. If I am correct, this discovery represents a substantial contribution to the dialectic because it offers philosophers and linguists substantial motivation to diminish their reliance on disagreement data in the debate about the semantics of taste.
\end{abstract}

\section{Introduction}

Linguistic data derived from examples of gustatory disagreement often play a major role in deciding the correct semantics of predicates of personal taste such as 'tasty'. Interest in these predicates is generated in large part by the fact that these expressions appear to strain the familiar semantic framework of Lewis and Kaplan. ${ }^{1}$ In Lewis and Kaplan's view, truth-values of sentences are assigned relative to a context of utterance and a circumstance of evaluation that normally includes a possible world. However, it is unclear as of yet how to accommodate perspectival information such as standards of taste in this framework. Accommodating these terms is especially challenging because they appear to give rise to puzzling linguistic data in certain contexts of use, most notably in contexts of disagreement. In particular, some researchers claim disagreements involving

1. Kaplan (1989) and Lewis (1980).

Contact: Heidi Furey <hfureyo1@manhattan.edu> 
predicates of personal taste are 'faultless' in a way that normal disagreements are not. ${ }^{2}$

One common answer to this challenge, contextualism, attempts to explain faultless disagreement by arguing that predicates of personal taste are "context sensitive," that is, that sentences containing them express different propositions in different contexts. However, it has been argued that, given the contextualist approach, taste disagreements devolve into situations in which the participants hopelessly talk past one another. Call this, the "Problem of Talking Past." Because of this problem, it appears contextualists may not be able to offer a satisfactory explanation for taste disagreements. The apparent failure of contextualism on this count has led some philosophers - relativists - to modify Kaplan and Lewis's systems further in order to accommodate predicates of personal taste. According to relativism, sentences containing perspectival information express the same proposition in every context in which they are uttered. The truth of these propositions is relative to something like a taste perspective or standard of taste. Relativists claim their view fares better than contextualism in explaining faultless disagreement. However, it appears relativism faces its own challenges. In particular, relativists must explain how it could ever be appropriate for individuals with different standards to disagree given that truth is relative to a standard of taste. Call this, the "Problem of Inappropriate Disagreement." Thus, both relativists and contextualists have taken a substantial amount of time in trying to solve these problems in ways that are consistent with their semantic accounts. ${ }^{3}$

I think this approach is mistaken in several ways. First, the current trend of focusing on faultless disagreement produces an impoverished set of linguistic data. ${ }^{4}$ As I will demonstrate below, if we look beyond the simple examples of taste disagreements that often serve as the sole test cases for our intuitions, we find many of them do not appear faultless. Because of this, I argue the real puzzle surrounding taste disagreements is to explain both the fault and the faultlessness therein-a puzzle I argue resembles the famous Paradox of aesthetic taste first articulated by Kant. Second, I believe, contrary to the trend in the recent literature, much of the "linguistic data" generated by cases of taste disagreements - even the more robust data that I have argued exists-is really epistemic or meta-aesthetic data. ${ }^{5}$ t think this data can be accommodated inde-

2. For examples of philosophers and linguists interested in faultlessness, see Kölbel (2004), Lasersohn, (2011), MacFarlane (2005; 2007; 2014), and Stevenson (2007).

3. For example see Lasersohn (2011), MacFarlane (2005; 2007; 2014), Molttmann (2010), Stevenson (2007), and Schaffer (2011), Sundell (2011; 2016).

4. Jonathan Shaffer (2011) makes a similar point.

5. Timothy Sundell $(2011 ; 2016)$ also offers and explanation to what I'm calling the "Paradox of Taste." However, Sundell argues disagreements about taste are really about meta-linguistic issues rather than epistemic or meta-aesthetic issues. I will show, my account offers something 
pendently of the semantics by a theory of the purpose of taste disagreements. To this end, I develop such a theory-one that includes an appeal to distinctively gustatory norms. My account of the purpose of taste disagreements has the benefit of being neutral with regard to the semantics of "tasty." 6 If I am correct, this discovery represents a substantial contribution to the dialectic because it offers philosophers and linguists substantial motivation to diminish their reliance on disagreement data in the debate about the semantics of taste.

\section{Taste Disagreements and the Paradox of Gustatory Taste}

\subsection{Intuitions regarding "Faultless Disagreement"}

When thinking about taste, examples naturally come to mind of taste disagreements that contrast sharply with disagreements about empirical matters of fact. For instance, an episode of Rachael Ray's daytime talk show featured a couple involved in a culinary debate. Here's an excerpt from Rachael's website summing up the conflict:

Stacie and Mark have a disagreement about pasta. He'll only eat spaghetti, and she wants him to try rigatoni, penne ... anything other than spaghetti all the time! "I want Rachael to show him that there is a reason why you use different pastas with different sauces," says Stacie, hoping they'll solve their "noodle war" on the show. But when Rachael blindfolds him for a taste test, he still chooses spaghetti as his favorite! "You're stuck eating spaghetti the rest of your days," Rachael tells Stacie, giving her a gift certificate to Lupa, one of Mario Batali's restaurants. ${ }^{7}$

Most likely, Mark and Stacie's dispute is about many things. But whatever

Sundell's does not-a full explanation of the source of objectivity and a full explanation of the source of faultlessness in taste disagreements. Nonetheless, I think ultimately, Sundell's account is compatible with mine and together they are complimentary. It is my view that taste disagreements may have multiple purposes. It is likely some taste disagreements are not about tastiness at all, but are instead about the way we use the term "tasty." If that is the case, we may want to appeal to a separate semantic and pragmatic explanation of taste disagreements to handle linguistic or metalinguistic disagreements about "tasty." However, because my account is semantically neutral, it is happily paired with other accounts that treat linguistic and meta-linguistic disagreements.

6. In principle, I believe this account could be combined with a number of the leading semantic theories of taste to help explain taste disagreements. In this sense, my account is not a competitor to semantic accounts of predicates of personal taste. Rather, it could be seen as an enhancement of any one of these theories. However, space precludes me from fully demonstrating this claim here. In that case, I will set this point aside for now and focus on demonstrating how the data generated by linguistic examples of taste disagreement can be explained with reference to a theory of the purpose of taste disagreements.

7. http://www.rachaelrayshow.com/show/segments/view/a-couples-noodle-war/ 
else it may be, their argument is also a disagreement about taste. We can easily imagine Mark and Stacie standing in their kitchen participating in the following sort of dialogue.

(1) Stacie: Why don't we try rigatoni for dinner? Rigatoni is just as tasty as spaghetti.

Mark: No, rigatoni is not as tasty as spaghetti. Spaghetti is tastier than rigatoni!

When discussing gustatory matters, we sometimes appeal to the familiar expression "there is no disputing about taste" (or, for those who speak Latin, "de gustibus non disputandum est"). ${ }^{8}$ Of course, as the episode from Rachael Ray's show reveals, people dispute about taste all of the time. Clearly, by reciting the familiar Latin phrase we do not mean to say that we do not argue about matters of taste. ${ }^{9}$ Instead, what we seem to mean is that disagreements about taste often appear to be pointless in a way that other kinds of disagreements-disagreements about empirical matters of fact-for example do not. ${ }^{10}$ For instance, compare Stacie and Mark's dispute with the following fictional case of disagreement between Rachael Ray and Bobby Flay.

(2) Rachael Ray: Adding salt to the water makes it boil faster.

Bobby Flay: No way, Rachael! Adding salt to the water does not make it boil faster.

In (2), at least one person is mistaken in his or her judgment, either in the sense that they have been epistemically irresponsible or in the sense that they have said something false. The disagreement is in principle resolvable. There is some fact of the matter - a fact about the way the world is, in and of itself - that grounds the truth of each judgment. This objective ground determines who is mistaken. Assuming Rachael and Bobby are both rational and epistemically responsible people, the disagreement has a chance of being resolvable in practice as well as in principle. It would be relatively easy to obtain information about the relevant empirical facts in this case, and this information could serve as evidence for or

8. See Egan (2010) for an interesting discussion of what we mean when we say there is "no disputing about taste."

9. That is, unless you think these sorts of dialogues fail to qualify as disagreements at all. I think the real question is not whether these sorts of dialogues are disagreements - let us grant for now that the definition of "disagreement" is broad enough to include them. The more interesting question is how closely disagreements about taste resemble disagreements in other areas (scientific or moral disagreements, for instance).

10. Egan (2010) makes the point that, despite insisting taste is something about which there can be no dispute, we often do just that. Egan offers an alternative explanation for this fact. 
against either claim. If neither Bobby nor Rachael has direct access to the right empirical data, they could always appeal to the testimony of the relevant scientific experts to help settle the dispute.

Imagine Rachael is in possession of strong evidence for her claim. If Bobby considers Rachael to be an epistemically reliable source of information, then assuming he values having true beliefs, he has an epistemic reason to change his mind about the matter. If epistemic value is linked to any sort of epistemic obligation, then not only does Bobby have a reason to change his mind, he ought to change his mind. If Bobby meets his epistemic obligations (and if he does not mind admitting defeat), he may even retract his original claim, admitting he was wrong as in (3).

(3) Rachael Ray: The scientists at the Harvard lab have determined adding salt does make water boil slightly faster.

Bobby Flay: Really? Well, I guess I was wrong. Adding salt to the water does make it boil faster.

At first glance, Stacie and Mark's disagreement looks very different from Rachael and Bobby's disagreement. To begin with, it is not clear that either Stacie or Mark is mistaken in judgment. Both individuals seem to be "faultless" to some extent, either in the sense that neither of them has done anything epistemically improper, or perhaps even in the sense that neither one of them has said anything false. It seems natural to think part of the explanation for these differences is that matters of taste are grounded in some way in subjective experience, in addition to the way the world is otherwise. Furthermore, matters of taste seem closely connected in some way to personal preference. This is evidenced by the fact that someone involved in a taste disagreement may appeal to his or her own preferences in defense of their claim. This phenomena, called, entrenchment, is demonstrated in (4).

(4) Stacie: Rigatoni is just as tasty as spaghetti.

Mark: No, rigatoni is not as tasty as spaghetti. Spaghetti is tastier than rigatoni!

Stacie: Jeez, lay off. I was just saying that I like it.

If matters of taste are subjective in this way, then perhaps this explains why we have the intuition that neither Mark nor Stacie is mistaken in their claims. After all, how could it be possible for someone to err in a judgment of taste? Granted, there is some chance that someone could be mistaken about the content of his perceptual experience, or even that he could be mistaken about what he truly prefers. For instance, force of habit or sheer stubbornness could mask someone's 
true preferences. Perhaps this is the kind of mistake Rachael is trying to rule out by administering the taste test to Mark. But once it has been established that Mark really does prefer spaghetti to any other pasta, it seems pointless to try to persuade him of the tastiness of other pastas. And of course, the taste test does not prove that Stacie was mistaken in her judgment. Perhaps if Stacie were blindfolded and asked to choose, this test would show she liked all of the pastas equally well. Along the same lines, it is hard to imagine what could count as an epistemic reason in this case-it's hard to see what could epistemically motivate Mark or Stacie to change their minds. It certainly seems that neither Stacie nor Mark are obligated in any way to change their minds.

Given these observations, it is natural to think Stacie and Mark's disagreement is not only in practice irresolvable but also in principle irresolvable. ${ }^{11}$ After all, if man (or woman) is the measure of truth in matters of taste, and men (or women) differ with regard to their subjective experiences, then there is no external standard to which we can justifiably appeal in order to settle a dispute.

\subsection{Contradictory Intuitions}

Comparing an example like (1) with an example like (2) appears to vindicate the intuition that disagreements about taste are pointless and inconsequential. After all, the linguistic and epistemic practices of the participants in (1) look very different from the practices of the participants in (2). However, if we were to consider a wider range of examples of taste disagreements, we would find that in many cases the behavior of the participants in a taste disagreement does in some respects resemble the behavior of the participants in an empirical disagreement.

To begin with, there seem to be cases in which the conversational participants are attempting to change one another's minds about taste. Consider this ongoing debate

Between Ed and Jim about the taste of beer:

(5) Ed: Budweiser is tasty.

Jim: No, Budweiser isn't tasty at all! It's so watered down it hardly tastes like beer. Dogfish Head 6o Minute IPA, on the other hand, has a far richer flavor. If you started drinking more beer, you would see what I mean.

11. In his reply to Cappelen and Hawthorn, Lasersohn cites irresolvability as the reason that taste disagreements are often easily abandoned: "As many people have pointed out to me, people often drop a debate as soon as it becomes clear that it is over a matter of taste. It seems to me, however, that we do not drop such debates because our sense of disagreement has disappeared, but rather because we know that it is not resolvable" (Lasersohn 2011) 
Ed: Budweiser is tasty! It's crisp and refreshing. You've just ruined your palette with all of those over-hopped beers. You need to get back to the basics!

Here, it looks as though both Ed and Jim are attempting to persuade each other to change positions. Furthermore, they seem to be offering some kind of evidence for their positions. We can also find examples in which the conversational participants appear to appeal to gustatory experts, as in (6), or point to a large amount of inter-subjective agreement, as in (7), in order to make their cases.

(6) Lowell: Sam said that the Ravenswood Cabernet is tasty. Donovan: He's wrong. I read a review in Wine Spectator that said it wasn't. ${ }^{12}$

(7) Dan: The food at Pizza Hut is tasty.

Liz: No way! I've talked to a lot of people, and no one other than you thinks the food there is tasty.

Examples such as these give us reason to think some disagreements about taste involve a persuasive aspect. Here it should also interest us that such attempts at persuasion are often successful. For instance, we can think of examples in which individuals appear to have been successfully persuaded to change their minds, sometimes to the point of issuing a retraction as in (8).

(8) Jacob: This cheese is disgusting-I think it's rotten!

Katie: It's actually really tasty. It's aged, not rotten-it's supposed to taste a bit sour.

Jacob: [Tastes it again] I guess I was wrong. This cheese is tastier than I thought.

It seems that, at least in some of these cases, not only is each participant trying to change his or her interlocutor's mind, but the participants also think that their interlocutors ought to change their minds. If that is the case, then these examples

12. Although I find it natural to appeal to expert advice as the basis for a taste claim, not everyone may. As an anonymous reviewer pointed out, many philosophers insist (in the tradition of Kant) that judgments of taste must be made on the basis of firsthand experience. However, in disagreements about taste, we sometimes cite the taste of experts as evidence of what our tastes ought to be, not what our tastes currently are. Kant's view was that in cases such as these we are pointing to experts as aesthetic exemplars. 
also give us reason to think some disagreements about taste may have a normative aspect as well. ${ }^{13}$

\subsection{The Paradox}

At this point we are left with a bit of a paradox, or rather, a puzzle. When we examine cases like ( 1 ) and (4), disagreements about taste seem very different from cases of empirical disagreement. In cases like (1), the participants often fail to offer much evidence for their positions or appeal to experts to resolve their disputes. The disputes appear to be faultless in some sense, and it appears as though these debates are irresolvable both in principle and in practice. And if pressed an individual in a taste disagreement may always entrench as in (4). These sorts of cases leave us with the impression that taste disagreements are rather trivial. On the other hand, when we examine other cases of taste disagreements like (5), (6), (7), and (8), we get the impression that some disagreements about taste are more similar to disagreements about empirical matters of fact than we might have thought. In these cases, the conversational participants sometimes do offer evidence for their positions-evidence that seems designed to persuade their interlocutors. They appeal to experts and to inter-subjective agreement to resolve disputes, and they sometimes proceed as if there were normative constraints on the debate. In these cases, it looks as though there is some sense in which at least one of the participants is at fault, though the fault might not be a result of falsity or epistemic irresponsibility. Furthermore, some of these disagreements are resolvable both in principle and in practice. These sorts of cases leave us with the impression that disagreements about taste are not trivial. We can call this puzzle the "Paradox of Gustatory Taste" after the Kantian "Paradox of Aesthetic Taste." cPosition:Superscript $>14$ The Paradox of Aesthetic Taste plays a role in Kant's larger philosophical agenda, and as such, a full explanation of the paradox would require that we situate it within Kant's epistemological and metaphysical framework. However, we need not do that here. The heart of the paradox is about an issue that arises independently of Kant's other philosophical projects. The Kantian paradox essentially involves explaining how aesthetic judgments, such as judgments about beauty, can be both objective and subjective-a seemingly impossible task. Likewise, the "Paradox of Gustatory Taste" involves explaining a seemly contradictory set of intuitions regarding taste claims.

13. I have been using examples in which the participants use "tasty" rather than examples in which the participants use expressions like "tastes good" or "is good." I think we might have even stronger intuitions about the persuasive and normative aspects of taste if we were to look at cases involving "tastes good" or "is good" than we do for cases involving "tasty."

14. See Kant's Critique of Judgment (1987). See also Schellekens (2009) for a summary of the Paradox of Aesthetic Taste and its relationship to Gustatory Taste. 
Here a note on the paradox itself is in order. To begin with, The Paradox of Taste-be it gustatory or aesthetic - is not a paradox in the formal sense. Rather, it is a problem of how to understand two contradictory data sets. Second, there are several candidates for what counts as data in this discussion. And there are several possibilities for what kind of solution is called for in the explanation. The Kantian version of the paradox refers to judgments of taste, not intuitions regarding linguistic examples. His aim was to articulate how judgments of pure beauty - such as judgments of natural beauty - could be based on "sentiment" and yet demonstrate "universal validity" in the sense of having some kind of normative force. In other words, when we call something beautiful, we do so on the basis of feelings of pleasure, and yet we expect everyone ought to agree with us. Although Kant sometimes used language as a guide to elicit intuitions regarding judgments of taste, his ultimate goal was to offer an analysis of judgments of beauty not judgments of "beauty." One contemporary interpretation of the paradox of taste is as a puzzle about how judgments of beauty can be grounded. In other words, how judgments of taste can be based on reasons. For instance Roger Scruton characterizes the paradox this way:

The paradox, then, is this. The judgement of beauty makes a claim about its object, and can be supported by reasons for its claim. But the reasons do not compel the judgement, and can be rejected without contradiction. So are they reasons or aren't they? (2009: 7)

Scruton's claim is that the reasons that support judgments of taste are compelling, but not necessarily rationally compelling. This is because one can reject such reasons without being irrational. The puzzle involves how judgments of beauty can be grounded without appealing exclusively to epistemic norms.

The paradox of gustatory taste can be articulated without reference to linguistic examples, by pointing to our intuitions about judgments of beauty, describing our behavior regarding beautiful items, or even offering a list of philosophical "platitudes" regarding gustatory taste (as Scruton does when he articulates a collection of platitudes regarding beauty). However, I've chosen to employ linguistic examples for two reasons. First, as I mentioned in the introduction to this paper, linguistic examples of taste disagreements often play a substantial role in the contemporary debate regarding the semantics of predicates of personal taste such as "tasty." If I can show that such examples can be accommodated without reference to a semantic theory, than it ought to diminish the role of these examples in semantic theorizing. Second, I assume that one way of discovering what sorts of reasons we offer is to consider our actual or possible linguistic practices in taste disagreements. Granted, it could always be that our linguistic behavior has no connection with the potential grounds of gustatory disagreement. How- 
ever, it would be psychologically odd if it turned out our linguistic practices had no connection whatsoever with either our implicit or explicit beliefs about the grounds of taste disagreements. For this reason, I take linguistic examples to offer a prima facie guide to what factors drive and potentially adjudicate our taste disagreements.

\section{Preparing to Resolve the Paradox of Taste}

In what follows, I will attempt to resolve the paradox. I will do so by offering a theory about the purpose of taste disagreements-one that explains the seemingly contradictory sets of intuitions involving gustatory disagreement. I believe focusing on the purpose of taste disagreements holds the key to solving the Paradox of Gustatory Taste. This is because whether one is in error or at fault in a disagreement depends on what goal or ideal a conversational participant has fallen short of. Likewise, whether it makes sense to offer evidence or appeal to experts in a disagreement depends on what the conversational participants are trying to accomplish. Finally, whether a disagreement is resolvable depends on the goal of resolution.

\subsection{Subjectivity and Error}

The first step in resolving the Paradox of Gustatory Taste involves rethinking some of our original assumptions about the nature of taste disagreements. At first it may seem natural to explain our intuitions about example (1) by making the following assumptions: taste disagreements are faultless because matters of taste depend on the subjective experiences of the individual-something about which the individual cannot be in error. They are irresolvable because there is no fact of the matter as to who is right in a taste disagreement. Accordingly, there is no such thing as evidence or experts in a taste disagreement. Although this sort of explanation might seem fitting for (1) and (4), it leaves cases like (5), (6), (7), and (8) mysterious. In that case, it may be worth challenging the assumption that the subjectivity of taste claims precludes an individual from being in error about a taste judgment. Likewise, it is worth questioning the assumption that there is never any fact of the matter as to who is right in a disagreement about taste.

Before I proceed, I want to take a moment to discuss what it means to say that matters of taste are subjective and to discuss why one might think the subjectivity of taste precludes error in taste claims. I will then argue that the real worry about the subjectivity of taste comes from the assumption that evaluative uses of taste claims are not connected to an objective set of gustatory norms. 


\subsection{Subjectivity and Sensations}

Much debate occurs about the nature of subjectivity and about how to distinguish objective matters from "merely" subjective matters. One way of defining objectivity is to say objective matters are those that depend somehow on the way the world is. As we have seen, it is natural, though not uncontroversial, to think that disagreements about empirical matters of fact, such as the one depicted in (2), are objective in this way. How should we characterize subjectivity? Since our goal is to make sense of a variety of taste disagreements, we should start out by characterizing subjectivity as neutrally as possible. At a minimum, it seems our intuitions about the subjectivity of taste require that matters of taste depend somehow on the individual. Here our characterization of subjectivity ought to allow for the possibility that matters of taste also depend somehow on the way the world is outside of the individual. For now, we can adopt the following characterization of subjectivity:

The subjectivity of taste: matters of taste depend at least in part on the way things are with the individual, in addition to the way the world is otherwise.

We can think of a variety of ways in which matters of taste might "depend on the individual." At the very least, we might think the properties involved in taste depend on the individual in the sense that these properties are response-dependent. Very roughly, response-dependent properties are powers of the object to reliably produce (under the right conditions) certain kinds of responses in individuals who are sensitive to them. ${ }^{15}$ If the properties involved in taste are responsedependent, then we might want to make the following assumption:

The sensation assumption: there exist some items in the world that have properties which, given a particular environment, reliably cause certain taste sensations in individuals with a similar physiological makeup and a similar experiential background. ${ }^{16}$

By "taste sensations" I have in mind physiological sensations such as sweet, bitter, and so on, that arise when an individual's taste receptors are excited by

15. My characterization of response-dependence is based on Davies (2006).

16. The sensation assumption will be somewhat controversial. For instance, we might wonder whether it is possible for an item to cause the same taste sensations in two individuals even given similar physiological makeup and similar experiential background. The sensation assumption does not say that individuals who have the same sensations will have the same preferences or evaluations. For a discussion about this point, see Dennet (1992). 
substances like sucrose, quinine, and the like. ${ }^{17}$ I will also use "taste sensations" more broadly to cover experiences of flavor, which results from things like postnasal olfaction in addition to literal taste; ${ }^{18}$ and to cover mouth feel, which is the result of an item's texture.

Is response-dependence responsible for the intuition that one cannot be in error about matters of taste? One could argue there is no fact of the matter as to whether something is truly bitter because sensations of bitterness may vary depending on the physiological makeup of the individual perceiving them. However, I think intuitions about the faultlessness of taste disagreements are not primarily generated from the fact that taste sensations can vary from person to person. After all, human beings have similar enough taste sensations that we usually judge bitterness, sweetness, and the like on the basis of an inter-subjectively determined standard. Although the status of properties like bitterness is controversial, we can set it aside for now. The real worry about the subjectivity of taste comes from something deeper than worries about the response-dependence of taste sensations.

\subsection{The Real Worry about Subjectivity}

The subjective experience of taste involves more than just taste sensations. We have a whole host of responses and reactions to those sensations, and to the items that give rise to the sensations. We can think of the relationship between the sensations caused by gustatory items and the responses and reactions that we have to those items and sensations as underlying a sort of gustatory point of view, what I will call a taste perspective.

Taste perspective: a complex of dispositions to respond or react to the sensations produced by gustatory items, or to the gustatory items themselves.

Among the responses and reactions involved in a taste perspective are things like taste preferences: likes and dislikes with regard to taste. They may also include things like taste evaluations: beliefs or attitudes about which gustatory items or experiences are better or worse than others. The real worry about the subjectivity of taste comes from the fact that matters of taste are somehow grounded in taste perspectives. One version of that worry begins with the idea that evaluative judgments about taste are grounded in our taste preferences. It is then assumed that it is impossible for an individual to be mistaken about her preferences be-

17. For a brief overview of the physiology of human taste, see Bowen (2006).

18. Here I am drawing on Bartoshuk and Duffy (2005), who distinguish between literal taste and flavor. 
cause individuals have perfect access to information about their own likes and dislikes. In that case, it is impossible to be in error about our preferences. Furthermore, it is assumed there are no further grounds for what preferences we ought to have. If this is true, then it is impossible to be in error about which preferences we ought to have.

There is reason to think an individual could be mistaken about which gustatory items he truly prefers. For instance, it might be that Jim thinks he likes the taste of Guinness for itself when really he likes to be seen drinking a more expensive beer. ${ }^{19}$ In that case, perhaps the purpose of some taste disagreements is to discover what an individual's true preferences are-to separate out preferences that are based on the way the object tastes from the preferences that are based on things like social pressures or advertising appeal. However, the worry remains that, once a person's true preferences have been established, no right or wrong answer exists as to which preferences she ought to have and no substantive reason exists for her to change her mind about her preferences. In other words, there do not exist gustatory norms that govern gustatory disagreements in the way that there exist epistemic norms that govern empirical disagreements.

\subsection{Beyond Descriptions: The Persuasive and Normative Aspect of Disagreement}

If we assume that matters of taste are subjective in the sense that there is no right answer as to what tastes one ought to have, then it is natural to assume that the purpose of disagreements could only be to express or describe ones preferences (or the preferences of one's conversational group.) Certainly, expressing or describing our preferences or mapping out a common preferential ground must be part of the reason for engaging in taste disagreements. And perhaps in many cases of taste disagreement it is the sole purpose. After all, there will be many cases in which it is not clear to the conversational participants what preferences they have in common, and there are many practical decisions that rely on commonality. However, if discovering the tastes of the conversational participants were the sole purpose of a disagreement about taste, we would expect these disagreements to terminate once the conversational participants knew where each of them stood with regard to their tastes. And yet, it is not difficult to imagine cases of ongoing disagreement such as (9) in which the disagreement continues long after the participants have fully cataloged the tastes of the group.

19. My example here has to do with mistakes about the contents of our preferences. However, Nisbett and Wilson's (1977) paper, which gives reason to doubt that we have perfect (or even very good) access to our cognitive processes, might also be relevant. 
(9) Mark: I'll say it again - spaghetti is tastier than rigatoni!

Stacie: So you keep telling me, but you're wrong. Every kind of pasta tastes exactly the same. Why can't you see that?

Furthermore, claiming the goal of taste disagreements is merely descriptive or expressive will not help us explain taste disagreements in which it appears the conversational participants are attempting to change one another's minds. Call this the persuasive aspect of taste disagreement in order to distinguish it from the expressive or descriptive aspect. If the point of taste disagreements were for the participants to give each other information about their own tastes or to discover what tastes the participants had in common, there would be no call for the participants to offer evidence in defense of their tastes. Likewise, there would be no need to call upon experts to settle the dispute, because each person is more or less an expert with regard to how things taste to him or her at any given moment. Finally, if the goal is merely to describe or express, then we would not expect to see a normative aspect to disagreements - cases such as (10) and (11) in which it looks like the conversational participants think their interlocutor ought to change his or her mind. ${ }^{20}$

(10) Robert: This cheese steak I bought at the gas station is tasty! Mac: Oh brother, are you wrong about that. You need to have a real Philly Cheese Steak — now that's tasty! Try one and you'll see what I mean.

(11) Bobby: This stale pizza is tasty!

Lisha: No it isn't. You're just high, so you think everything is tasty. Cases such as these make it clear that while part of the point of disagreeing about taste may be to express or describe taste experiences, sometimes there is more to it than that. There is sometimes a persuasive and even a normative aspect to taste disagreements as well.

\section{Why Disagree about Taste?}

\subsection{Taste Disagreements and Coordination}

What else could we be doing in a taste disagreement besides describing and expressing our tastes (or the tastes of the conversational participants)? One sug-

20. I am not claiming that all taste disagreements involve a persuasive or normative aspect, only that some do. 
gestion is that in some cases we are also trying to coordinate our tastes. More specifically, I think we are trying to coordinate our taste perspectives, either by attempting to make our dispositions more similar to those of our interlocutors or by trying to convince our interlocutors to cultivate dispositions that are more similar to our own. The process of coordination is something disagreements about taste have in common with disagreements about empirical matters of fact. Often, part of what the individuals in empirical disagreements are trying to do is to coordinate their epistemic perspectives. ${ }^{21}$

When I say that part of what we are trying to do in taste disagreements is to coordinate our taste perspectives, I do not mean to say that coordination itself is the ultimate goal of taste disagreements. Perhaps coordination has some value in and of itself. If this is so, then there will be cases of taste disagreements and empirical disagreements in which coordination is the sole purpose of disagreement. However, in most cases some reason must exist for coordination, even if it is purely pragmatic. In these cases, coordination is a means to obtaining some further value, and not itself the ultimate goal of the disagreement.

\subsection{Is Taste Coordination Possible?}

Before we discuss the value of taste coordination, we should ask whether taste coordination is even possible. Assuming that taste perspectives involve dispositions, we need to ask whether it is possible for us to alter our responses or reactions to a gustatory item. I am assuming that our responses and reactions to a gustatory item include not only experiences but beliefs and evaluations as well. So, although I have used the phrase "change of mind," we should take this phrase to include changes in experiences as well as changes in beliefs or judgments.

There are a variety of ways to influence a person's taste perspective. To begin with, our reactions and responses depend in part on our taste sensations. Given the sensation assumption, taste sensations depend on a number of things, including the properties of the item being tasted, native physical and psychological makeup (what I will call natural sensitivity), the conditions under which an item is tasted (what I will call the taste conditions), and palate development (what I will call gustatory training or gustatory education). We have limited, if any, con-

21. There is some debate about how to characterize epistemic perspectives and what sort of beliefs epistemic perspectives should include. I will not go into details here about the exact characterization of an epistemic perspective. For now, we can represent an epistemic perspective as a credence function or collection of credence functions. There is no further restriction that these beliefs be cases of knowledge. In that case, it may be more appropriate to use the expression 'doxastic perspective' instead of 'epistemic perspective.' I will continue using 'epistemic perspective' here to remain consistent with the literature on the semantics of epistemic modals, a literature related in important ways to the semantics of taste. 
trol over the properties of an item or over our natural sensitivity. Our natural sensitivity can change over time, but not usually in ways that are under our control. ${ }^{22}$ For instance, we often become less sensitive as we grow older. However, we have some degree of control over taste conditions and over gustatory training. For instance, with regard to environmental control, the temperature of an item can affect our taste sensations. We may experience more flavor when an item is brought to room temperature than we would have if it were chilled. Items we have tasted immediately before tasting that particular item can also affect our taste sensations. With regard to gustatory training, there is no shortage of books and articles that explain how to develop our palates. ${ }^{23}$ These texts encourage us to heighten our sensitivity or awareness by paying attention to what we taste, tasting often, tasting broadly, and so on.

Of course, there are many other ways to influence someone's responses or reactions to an item that do not necessarily involve changing her taste sensations. For instance, each person has an experiential and doxastic background relating to taste. Your gustatory background, as I'll call it, includes things such as experiences relating to gustatory items, memories or feelings you have associated with a gustatory item, beliefs about the quality or origin of the item, your contextual relation to a gustatory item, and so on. Your gustatory background affects your reactions and responses to a gustatory item. For instance, positive associations with an item, such as a happy childhood memory, might enhance your enjoyment of the item. On the other hand, negative associations with an item, such as a memory of sickness after eating this item, might decrease your enjoyment of the item or even foster disgust. Likewise, in a context in which someone has a limited selection of gustatory items or is especially hungry, an item might give more pleasure than it would if it were tasted in a context in which someone had a large selection available or was sufficiently sated. The beliefs we have about an item can also affect our reactions and responses. For instance, discovering a dish was made of rat intestines might alter a person's responses.

It is also possible that simply hearing about other people's preferences or evaluations could cause you to alter your own preferences or evaluations to some extent. For example, a study by Plassmann, O'Doherty, Shiv, and Rangel (2008) appears to show that information regarding marketing factors, such as price, can affect neural representations of perceived pleasantness in wine drinkers. When participants were told, contrary to fact, that the wine they were drinking was more expensive (a factor most wine drinkers associate with higher quality), they reported having a more positive subjective experience of the wine. More interestingly, MRI scans of the participants showed an increase in the blood-oxygen-

22. There are some exceptions. We could lessen our natural sensitivity by damaging our taste faculties by smoking.

23. For example, see Teague (2007). 
level-dependent activity in the medial orbitofrontal cortex - the area thought to be responsible for encoding experienced pleasure during experiential tasks. Although the study does not actually prove that information regarding the price of wine affects how much pleasure a wine drinker experiences, it does suggest external information can affect our subjective experiences of an object. If that is the case, than not only could the testimony of gustatory experts provide a reason to alter our preferences; simply hearing such testimony might itself alter our preferences to some extent.

Linguistically, there are many ways to persuade someone to change their tastes. Sometimes we may try to change a person's tastes directly by changing the way things taste to them. For instance, sometimes someone can get you to change your mind about the way something tastes by getting you to notice certain properties of an item or experience you hadn't noticed before. The next time you taste the item, you may have a different taste experience. On the basis of this new experience, you may change your position on the tastiness of the item. This seems to be what is going on in (12).

(12) Heidi: Why didn't you order strawberry jam? Orange marmalade isn't tasty at all.

Tonya: Orange marmalade is tasty; you just don't know what to look for. The bitterness of orange rind perfectly complements the sweetness of the jam.

Heidi: [Tastes it again] You know, you're right. Orange marmalade is tasty.

Sometimes we may try to change someone's tastes indirectly by changing the person's beliefs about what his or her taste experience ought to be. ${ }^{24}$ Individuals will retract their previous claim even without acquiring a new taste experience. For instance, sometimes it seems appropriate for someone to retract a claim on the basis of testimony alone. In (13), Helen and Jeff are at a wine tasting put on by the local wine-and-spirits emporium. Helen is a connoisseur, while Jeff has very little experience with wine.

(13) Helen: What kind of wine are you interested in buying?

Jeff: Franzia is tasty.

Helen: Believe me, Franzia is not tasty.

Jeff: Oh, then I guess I was wrong.

24. We may also have beliefs about the way things ought to taste to us, and at times we may try to coordinate these beliefs even in cases in which there is no hope that our taste experiences may be coordinated. 
If someone is an expert, then merely hearing that this person disagrees with you can give you reason to change your mind or to retract what you said. This can be true even in cases in which your own taste experience of the world has not changed. ${ }^{25}$ In certain cases, testimonial evidence can be made even stronger if a number of testifiers agree on a subject. This explains why, in (14), Donovan should refer to the opinions of people outside the conversation when he argues with Jeff.

(14) Jeff: Busch beer is tasty.

Donovan: You're wrong; it isn't tasty. And everyone I know agrees with me.

\subsection{Why Coordinate?}

Now that we have explored whether it is possible to coordinate our taste perspectives, we can return to inquiring about the purpose of coordination. ${ }^{26}$ What kind of value might we be trying to achieve by coordinating our taste perspectives? It may help to start by considering the purpose of epistemic coordination, and asking whether gustatory coordination has a similar end. John MacFarlane offers the following suggestion regarding disagreements involving epistemic modality-epistemic uses of "might" and "must":

In the case of epistemic states, it is manifestly in our interest to share a picture of the world, and to learn from others when they know things that we do not. (MacFarlane 2007: 21)

Whose epistemic picture of the world is it in our interest to share? The answer depends on what our interests are. For instance, it might be in our interest to share a picture of the world because it would help us to get along better, to integrate with a social group, to achieve financial gain, and so on. In these cases, pragmatic value determines whose picture of the world it is in our interest to

25. In conversation, Tonya Manucharova provided me with an example that is an even better illustration of how a person could change her mind without acquiring a new taste experience. Her example shows that someone who has lost her sense of taste can nonetheless agree that an item is tasty on the basis of testimonial evidence. Manucharova's example is especially interesting because, in this case, there isn't even the possibility that the person can acquire a new taste experience.

26. MacFarlane (2007) points to coordination of "contexts of assessment" as a reason for taste disagreement while Sundell $(2011 ; 2016)$ makes use of meta-linguistic coordination in explaining the purpose of taste disagreements. My account of coordination differs from theirs in that coordination primarily involves a change in taste perspective (though it could involve coordination of contexts, standards, usage, etc., as well.) 
adopt. In some cases where pragmatic value is at issue, it may not even matter whose picture of the world we adopt so long as we share a picture of the world. Consider a case like (15), in which Paul and Meghan are utterly exhausted from arguing about football.

(15) Paul: The Cowboys won Super Bowl X!

Meghan: No, they didn't! The Steeler's won Super Bowl X!

It may be of great pragmatic value for Paul to concede to Meghan, even to the point of changing his belief. However, provided that it would be just as easy for Meghan to change her mind, then this pragmatic goal might be accomplished just as well if Meghan coordinated her beliefs with Paul's-regardless of the facts. In this case, marital harmony is motivating coordination-pursuing the truth might even get in the way of achieving that goal. It is clear, then, that pragmatic value can offer us some reason to change our minds in certain cases of empirical disagreement. However, as MacFarlane seems to suggest, a more objective reason exists for epistemic coordination. In many cases, it is only in our interest to coordinate our picture of the world with that of our interlocutor, so long as our interlocutor has a more accurate view of the world than we do. Consider (16), in which Stacie and Mark coordinate their beliefs about the direction of the finish line during an orienteering competition.

(16) Stacie: The finish line is to the north. The trail is much more worn in that direction.

Mark: No, the finish line isn't to the north. The map says it's to the south.

Assume the finish is actually to the south. If Stacie and Mark want to finish the race, then it is not in either of their interests to share Stacie's picture of the world. This is because in this case, although there is a pragmatic value involved (i.e. , finishing the race) obtaining it depends on obtaining a kind of epistemic: having true beliefs about the location of the finish line. Appealing to certain kinds of pragmatic value might help explain our behavior in certain kinds of disagreements about empirical matters of fact-cases such as (16), for instance. However, it is the pursuit of epistemic value that best explains the persuasive and normative aspects of certain disagreements. If empirical disagreements are most often driven by the pursuit of truth, then it makes sense we would use epistemic norms to determine what counts as evidence in a disagreement, who counts as an expert, and who is right. 


\section{The Value of Taste Coordination}

\subsection{Questions about the Value of Taste Coordination}

Is gustatory coordination driven by the same sorts of values as empirical disagreements, and hence regulated by the same sets of norms? So as not to assume too much, we can call the kind of value that could motivate taste coordination gustatory value, to distinguish it for now from other kinds of value. Part of our project will be to discover the nature of gustatory value and how it relates to other kinds of values. ${ }^{27}$

The value of taste coordination does not seem to be just about gaining knowledge of the world outside of our taste perspectives - though it may be about that too. Nor does gustatory value seem reducible to gaining knowledge of our own perspectives. Granted, we may want to have true beliefs about the world and about ourselves, even when it comes to taste. However, there seems to be some further reason in gustatory disagreements why we are motivated to have accurate beliefs of the world and ourselves. This is evidenced by the fact that disagreements about taste persist long after the disputants are clear on the relevant empirical and subjective facts. In (10) for instance, not only is Mac interested in presenting Robert with "the facts" about the tastiness of a real Philly Cheese Steak, he won't be content until Robert learns to appreciate it as well. In a case like this, Mac hopes that a change in Robert's belief will be action guiding - that a change in belief will lead to a change in perspective.

In that case, gustatory value does not seem to be reducible to epistemic value, although we can leave it open as to whether having more true beliefs about the world could be a means for obtaining gustatory value. Nonetheless, we still make use of epistemic norms in gustatory coordination-we appeal to experts, cite evidence, and so on. Could it be then that gustatory value is connected with a kind of prudential value and prudential norms determine rightness, evidence, and expertise? Certainly. There are all sorts of practical reasons we could have for coordinating our tastes. Here are just a few: it could save arguing over what to have for dinner, it could help us fit in culturally or socially with certain groups, it could even help us learn to tolerate a loved one's cooking! While these are all legitimate and compelling reasons to coordinate tastes, appealing to these sorts of reasons won't help us explain why, in many cases, one way of coordinating a taste perspective seems better than another way of coordinating. Consider (17) and (18).

27. Here I should note that, although I do make some suggestions about the nature of gustatory value, I am using the notion of gustatory value mainly as a placeholder for whatever sort of value ultimately motivates taste coordination. I do not intend to commit myself to realism about gustatory value. As for now, I will remain neutral about the ultimate meta-ethical status of gustatory value. 
(17) Student: Boone's Farm is tasty! I can't imagine drinking anything else.

Connoisseur: You're wrong. Boone's Farm isn't tasty. You need to branch out a bit, and you'll see what I mean.

(18) Ed: The fish sticks on campus are tasty. I could eat them for every meal.

Phil: I hate to break it to you, but the fish sticks on campus are really not tasty. You've just been in the dorms so long that you've forgotten what real food tastes like.

Setting aside pragmatic reasons like social acceptance or financial concerns, we can ask, does the connoisseur have just as much reason to change her tastes as the student has to change his? Will Phil benefit just as much from changing his tastes, as Ed will from changing his? If the answer to these questions is "no," then this points to there being a more objective source of gustatory value than the situation-based values I listed earlier. Of course, gustatory reasons and pragmatic reasons may come into conflict with one another. In claiming that there exists a more objective source of gustatory value that can guide coordination, I am not ruling out that there can be cases in which pragmatic reasons "trump" the more objective reasons. For instance, if Phil loses his job and can only afford campus food, it may be in his interest to develop a taste for fish sticks. Likewise, if the student is worried about being made fun of by his fellow undergraduates for drinking a "snooty" wine, then perhaps he has reason not to develop a taste for it. However, the real question is whether there are reasons for coordinating one way or the other that do not rely on idiosyncratically determined types of pragmatic value. If there are, then although we can still make use of prudential values in explaining part of the motivation for taste coordination, adding a more objective source of value will give us a more unified explanation of the normative dimension of these cases. ${ }^{28}$ In the following sections I will present a theory

28. Plunkett and Sundell (2013) are among the few philosophers who have attempted to offer an explanation of the normative aspect of taste disagreements. Their excellent account appeals to meta-linguistic reasons for coordinating uses of the word "tasty." Their goal is to give a semantic account of disagreement that is compatible with normative examples of taste disagreement. However, by Sundell's own admission, they are not attempting to offer a full explanation of the grounds of taste disagreement. This is especially clear in cases in which it seems there is an objective value at issue. For instance, Sundell (2016) says, "Sometimes speakers will aim to find a standard that corresponds to what they find pleasing, or will be disposed to find pleasing. Sometimes they'll aim for a standard that corresponds to what their clients, or their dog, or idealized humans under perfect conditions will find pleasing. Sometimes, perhaps, they'll aim for a standard that carves the world at the gustatory joints, the standard that reflects the true nature of the objectively perfect cupcake. Whether that goal makes any sense is a matter for aestheticians and metaphysicians and dessert chefs to figure out. But speakers can talk that way, and so the semantic theory 
of the purpose of disagreement that relies on a more objective source of gustatory value. I will then briefly articulate how this theory helps resolve the Paradox of Gustatory Taste.

\subsection{Aesthetic Value}

Drawing on Hume's essay On the Standard of Taste (1875), Peter Railton (1998) offers a theory of the grounds of evaluative aesthetic judgments that can help us discover a more objective source of gustatory value. Railton speaks mainly about aesthetic taste-he focuses on beauty rather than tastiness - but his views about the nature of aesthetic value are easily applicable to gustatory taste. ${ }^{29}$ Railton argues there are real, objective properties of certain objects in the world that reliably cause certain kinds of aesthetic experiences in us. He calls the properties that cause these experiences in us the beauty-making characteristics, and he calls the kinds of objects that have these properties beautiful objects. What kinds of experiences do beauty-making characteristics give rise to in the individuals who are sensitive to them? Railton thinks the answer is intrinsically sought-after experiences.

Which experiences are intrinsically sought after? Assuming that a more basic reason exists as to why some experiences are intrinsically sought after, a likely candidate for the source of their desirability is pleasure. Of course, it is debatable whether there is such a thing as an intrinsically sought-after experience, and also whether all and only intrinsically sought-after things are pleasurable. For our purposes, we will make use of the notion of pleasure while keeping in mind that, in the end, we may want to appeal to something broader. In addition, we ought to think of pleasure or intrinsic desirability as a source (or partial source) of aesthetic value while remaining neutral on whether it is the only (or complete) source of gustatory value..$^{30}$

should leave room for it. The semantic theory itself is metaphysically neutral. It makes room for any metanormative theory of gustatory value that you like, but itself makes no commitments" (2016: 21). A virtue of the account I present is that it is neutral with regard to the semantics. In that case, we can see it as complimentary to Sundell's project-as offering an explanation of a factor that could drive more objective examples of taste disagreements: gustatory value. Furthermore, although my account offers a fuller explanation of more objective cases of taste disagreement, it does not rule out that some taste disagreements are not motivated by the pursuit of gustatory value. For example, perhaps some taste disagreements are purely, linguistic, meta-linguistic, driven by social goals, etc.

29. Although Railton focuses on judgments of beauty rather than judgments of gustatory taste, he often follows Hume (1875) in using gustatory examples to illustrate his points. Insofar as it seems that Railton assumes that gustatory value is a kind of aesthetic value, perhaps he intends to give an account of both kinds of value simultaneously. Since I do not want to make any assumptions yet about the nature of gustatory value, I will treat it as being distinct from aesthetic value while noting that Railton might have intended to offer a united explanation of the two.

30. I think it is likely that gustatory value is something more complex than just pleasure. For instance, it may be that for some artifacts, gustatory value has something to do with skill or crafts- 
Railton, borrowing again from Hume, claims that some objects naturally fit with our faculties in such a way as to cause us pleasure. He calls this relation a match (1998: 67). Although pleasure is a subjective experience of the individual, the relation between the object and the individual is objective. According to Railton's view, there is a fact of the matter as to whether an object matches human sentiment. At this point it seems natural to ask, "If aesthetic value is grounded in a certain match between the properties of objects and human experience, then why are matters of taste debatable? After all, isn't each of us an expert when it comes to knowing what pleases us?" According to Railton, having expertise in what pleases us, as individuals, may not be enough to qualify any of us as aesthetic experts. This is because aesthetic value is not grounded in what is pleasurable for the individual alone. It is grounded in matches for human beings in general. Not only is aesthetic value grounded in something broader than individual pleasure, it is also grounded in something more substantial than momentary pleasure. Railton elaborates on what he calls a field of aesthetic value:

There will be some things that excel in their match with our sensibilities, and that can become a source of durable pleasure or interest, as familiarity grows, independently of otherwise large variations in personal experience, situation, or culture. (1998: 74, emphasis added)

According to Railton, the items that make for excellent matches are the sort of things that can act as reliable sources of pleasure. These are pleasures that are common across time and culture, pleasures we do not outgrow as we develop and refine our sensibilities. Speaking of beauty-making characteristics, Railton explains, "These features engage our sensory and cognitive capacities and our sentiments in ways we find intrinsically enjoyable, the more deeply and intensely so upon greater familiarity and broader experience" (1998: 76).

Railton thinks any of us, or even many of us, could be misled about what things robustly or durably match our sensibilities. ${ }^{31}$ This kind of error has a variety of causes. For instance, we may lack a natural sensitivity, we may be overly influenced by aesthetic trends, or we may lack experience or understanding. However, some people are less likely to err in these ways. These expert judges, as Railton calls them, are especially good at judging which things will be robust and durable sources of pleasure. How does one become an expert judge? In part, expertise has to do with how naturally sensitive one is to beauty-making characteristics. But it is also a matter of developing one's sensibilities by un-

manship. Consider, for instance, the skills involved in "plating" food in a fine restaurant.

31. I hope not to misinterpret Railton by referring to "robust and durable matches" or "robust and durable pleasures." It could be that Railton thinks only matches are more or less robust and that their robustness is due to how durable the pleasure associated with them is. 
dergoing a kind of aesthetic training. Those who are aesthetically well trained have had extensive practice with aesthetic items; they have built a comparative base by experiencing a wide range of items. Finally, being an aesthetic expert involves diligence in following certain epistemic principles. For instance, being an expert judge means that you utilize your natural sensitivity and training when making evaluative aesthetic judgments. Furthermore, because aesthetic value is grounded in something broader than what is pleasing for an individual or a culture, Railton thinks that the judgments of aesthetic experts must be free from personal, cultural, and sociological biases.

Although experts are more likely to be in tune with what is robustly and durably pleasurable to human beings, they are not infallible. However, when experts coordinate their beliefs, they increase their reliability. Perhaps it is because of this phenomenon that Railton follows Hume (1875) in saying the "joint verdict" of expert judges determines an independent standard of aesthetic goodness, or standard of aesthetic taste. However, rather than interpreting Hume as saying that a standard of taste is determined by the joint verdict of expert judges, Railton takes Hume to be arguing that the joint verdict of expert judges serves as a guide to or evidence of an objective standard of taste. ${ }^{32}$

While some things make for better matches than others, in some cases it is metaphysically indeterminate whether one item is a better match than another. This is in part because matches are, according to Railton, genre-specific to some extent. So while the music of Coltrane and the music of Beethoven are both beautiful, it could be that neither one of them provides a better overall fit with human faculties.

\subsection{Gustatory Value: A Major Motivation for Coordination}

We can straightforwardly apply much of Railton's theory of aesthetic value to help understand the nature of gustatory value. In order to fully explain our behavior in taste disagreements, we will need to rethink some of Railton's account. I will discuss modifications momentarily, but for now we will look at how Railton's account can help us begin to answer questions about the purpose of coordinating our taste perspectives.

To begin with, the idea of a match between human sentiment and certain items in the world is just as plausible for gustatory taste, if not more so, as it is for beauty.

Here we might recognize gustatory parallels for beauty-making characteris-

32. I am not certain Railton would agree that a standard of taste is determined by the joint verdict of the experts because coordination among experts increases reliability. 
tics and beautiful objects: tasty-making characteristics and tasty objects. 33 By possessing tasty-making characteristics, tasty objects fit with our faculties in such a way as to cause us gustatory pleasure. ${ }^{34}$ The suggestion that the source of aesthetic value has something to do with intrinsically sought-after experiences carries over well to the gustatory case. If gustatory value is linked to intrinsically sought-after experiences, in particular to gustatory pleasure, this helps explain the intuition that tastiness is closely connected with our gustatory preferences and evaluations. If there were a standard of gustatory taste that mirrored Railton's standard of aesthetic taste, this could help us explain why it sometimes seems that one way of coordinating a taste perspective is better than another. If there is an independent standard of gustatory taste, then it makes sense to defer to those whose tastes are more in line with this standard - those with more gustatory expertise. Of course, some people could care less about following expert advice. Is there something incoherent or irrational about the behavior of such people? Railton thinks there is not. He explains that their mistake is more like a missed opportunity than an epistemic error.

Putting all of this together, we see how Railton's framework can help us begin to understand why it is sometimes in our interest to change our tastes. One very broad reason is that, in certain cases, failing to do so could cause us to miss out on an important source of gustatory value: gustatory pleasure. 35,36

\section{Changes and Additions to Railton's Account}

Borrowing Railton's notion of a match helps us begin to explain the persuasive and normative aspects of taste disagreements. However, a full explanation requires a number of additions to Railton's account and some departures as well.

33. What are the tasty-making characteristics? Unfortunately, this is a question best saved for another time. One option is to look to the literature on aesthetic value for ideas. For instance, perhaps balance, complexity, novelty, and the like are among the tasty-making characteristics. For more on the topic of aesthetic value, see Beardsley, Wreen, and Callen (1982).

34. Is gustatory pleasure a special kind of pleasure? My first thought is to say we ought to think of gustatory pleasure as restricted to the kinds of pleasure we obtain through tasting edible items. I hope to explore more fully the nature of gustatory pleasure and its relation to other kinds of pleasure in future work.

35. What kind of value is gustatory value? In order to say what kind of value gustatory value is, we would have to know more about the nature and source of other kinds of value. For instance, it could turn out the ultimate source of positive moral value is pleasure, in which case gustatory value and moral value would have the same source. I will leave it open for now whether gustatory value is reducible to or connected with another kind of value, such as epistemic value, aesthetic value, pragmatic value, or moral value.

36. This explanation works for comments on past gustatory errors as well. For instance, we might say, "You thought the dim sum wasn't tasty? Well you're wrong. I bet you just didn't know what to expect. I'm sure if you tried it again you would change your mind." 
First, in the case of gustatory taste we need to allow for a kind of match that is characterized by something more idiosyncratic than a fit with general human sentiment (an issue I will address in Section 6.1). Second, we ought to consider expanding the relativity of matches to something beyond just species and genre (something I will attend to in Section 6.2). Finally, we should rethink what determines the goodness of a match - in particular, whether robustness and durability are the right metrics for determining the goodness of matches (a task I will take on in Section 6.3).

\subsection{General versus Local Matches}

As Railton acknowledges, we might be skeptical that there is, in fact, enough similarity between human beings, even among those with similar sensibilities and training, to allow for an actual field of aesthetic, or for our purposes gustatory, value. But even if there is enough similarity to underlie the existence of general matches, as I will call them, they play at most only a partial role in motivating taste coordination. There seem to be many cases of persuasive disagreement in which one or more of the participants are aware that their preferences are both idiosyncratic and in conflict with the standards set by expert judges. Consider (19), for example.

(19) Lily: I read a review that said there is nothing tasty to eat at the state fair.

Jacob: That's not true. I know there aren't many people who would agree with me (especially food critics), but deep-fried Oreos are really tasty!

If disagreements about taste were merely attempts to put someone in touch with items that could serve as robust and durable sources of pleasure to human beings in general, then Jacob's claim would be odd because he knows his tastes are in conflict with those of the general experts. To account for these kinds of cases, it will be useful to recognize matches grounded in individual sentiment as opposed to general human sentiment. This is the type of sentiment Hume (1875) called peculiar sentiment. We can call these sorts of matches, local matches to distinguish them from the general matches of Railton's account. 37

37. As a helpful anonymous reviewer has pointed out, if we think cases such as (19) are cases in which Jacob thinks that the expert is wrong, then there is no need to appeal to local experts. However, it seems to me that there could be cases in which, what we want to express is that someone is an expert for a certain group of people (connoisseurs, for instance) or for people in general, however that they are not an expert for people "like us." If that is the case, then this serves as some motivation for taking the notion of local expertise on board. 
General matches: objects that provide pleasure for the majority of members of a particular species.

Local matches: objects that provide pleasure to individuals with a certain kind of natural sensitivity or a certain kind of gustatory background.

Along the same lines, we should distinguish general gustatory experts from local gustatory experts. ${ }^{38}$

General gustatory experts: individuals who are good at detecting general matches.

Local gustatory experts: individuals who are skilled in detecting local matches, matches for those who are similar to themselves.

General gustatory matches determine a general gustatory standard of taste, and it is the general experts who are most knowledgeable about or sensitive to that standard. However, local matches determine a local standard of gustatory taste, and local experts are most knowledgeable about or sensitive to that standard. Which standard of taste it is appropriate to appeal to in order to settle a dispute will depend on which kind of match, if any, the disagreement aims at.

\subsubsection{Similarity and Expertise}

Because the notion of similarity plays a crucial role in the definition of local expertise, it is worth taking a moment to discuss what similarity involves. First, we should note that local or general gustatory experts do not actually need to be similar to those to whom they testify. All that is necessary is that gustatory experts are able to project themselves in the place of someone else such that they can form reliable beliefs about what kinds of things would be pleasurable to such a person. In that case, even someone with no sense of taste might be able to know on the basis of observation and testimony what sorts of things are pleasurable to another human being. Likewise, a human being might use projection to determine what things are pleasurable to another species.

Second, we should clarify what kinds of similarity matter for local experts. As the definition of local matches suggests, at least two broad kinds of similarity matter: natural sensitivity and gustatory background. Many factors influence the pleasure you get from an item, and hence must factor into the recommendations of a local expert. Furthermore, some of these factors are manipulable while some

38. If there are such things as local matches in addition to general matches, does this mean that there are two kinds of gustatory value? As of now, I have no answer to that question, though I hope to pursue the answer at another time. 
are not. Local experts have to be aware of both types of factors. A local expert may challenge an individual to change their tastes in cases where such a change would allow that individual better access to pleasure. However, there will always be physical limits on how much an individual is able to change. There is little point to challenging an individual to change when change is not possible. Consider, for instance, an example regarding the limits to cultivating natural sensitivity. For genetic reasons, certain individuals lack the ability to discern the presence of specific bitter compounds, such as phenylthiocarbamide, in foods. 39 No amount of gustatory training could alter the results of this genetic trait, and hence there could be no point in persuading an individual to try to change her tastes in this case. Likewise, although many components of a person's gustatory background can be influenced, some aspects will inevitably resist alteration. For instance, it may be that an individual's tastes are so deeply influenced by the range of gustatory items available in her culture that this limits the extent to which she could ever take pleasure in consuming certain items. Local gustatory experts must keep these sorts of unalterable facts about an individual's natural sensitivity, gustatory background, etc., in mind when making judgments and recommendations.

\subsubsection{Positive and Negative Biases}

Allowing local experts to be influenced by gustatory background stands in contrast to Railton's requirements for general experts. Again, Railton argues that general gustatory experts need to avoid "biases" such as personal experience and cultural background when making aesthetic (or gustatory) judgments. This is because general matches are a matter of what is pleasurable to humans in general, not to individuals with a particular gustatory background, etc. However, there is good reason for local gustatory experts to consider personal and cultural background when making gustatory judgments: these factors can positively affect the pleasure one derives from tasting an item. For instance, an individual raised in a culture with atypically spicy cuisine may enjoy items too intense for the "average" human. This individual has access to a source of gustatory pleasure that the average individual does not. Call these factors positive biases. Of course, not all biases are positive. There are some negative biases that local gustatory experts should avoid. Negative biases include factors that could influence a person's judgment but do not make a difference with regard to pleasure. For example, consider the marketing ploy propagated by gourmet market Whole Foods in which consumers were offered exorbitantly priced bottles of water con-

39. See Korsmeyer (1999) for an interesting discussion of issues relating to "the science of taste." 
taining nothing more than three stalks of asparagus. $4^{\circ}$ Presumably patrons could have been swayed in their opinion of the water merely by the branding and not the taste. But the type of pleasure they received from the item, if any, is hardly the robust or durable type. It seems clear then, that local gustatory experts ought to be free of prejudices held merely as a result of social influence, assuming such an influence does not affect the amount of pleasure associated with an item.

Of course, we might worry that, as I've defined things, the distinction between positive and negative won't necessarily be clear-cut. For instance, can't factors such as social influence positively affect how much pleasure an individual receives from an item? If they can, then it seems like they should no longer be considered to be a negative bias. At this point, it becomes difficult to draw a line between positive and negative biases. One way to handle this complication is to distinguish between pleasures that result solely from properties of the object itself and not from external factors. However, there are problems with that approach. External factors often influence how much pleasure we get from an item. Consider again, for instance, the 2008 study by Plassmann and colleagues that seemed to suggest beliefs about the price of wine not only influenced how much pleasure individuals reported experiencing from tasting the wine (a finding that is consistent with the subjects having false beliefs about the amount of pleasure they experienced), but it also affected neural paths. The latter finding suggests that the (false) information about the price of the wine actually increased the pleasure the subjects experienced when drinking the wine. Perhaps the best way to distinguish a positive bias from a negative one is not merely that a positive bias enhances pleasure, but that it enhances pleasure in a reliable way. For instance, social influence or price might temporarily affect how much pleasure we get from an item. However, because these factors often fluctuate unpredictably, they might not positively influence pleasure in a reliable way. If that is the case, then arbitrary social or financial factors will count as negative biases.

\subsubsection{The Role of Local Matches versus the Role of General Matches}

One final thing we ought to consider as we compare local and general matches is whether taste coordination is motivated primarily by the pursuit of local matches or general matches. In my view, local matches provide the main impetus for taste coordination (at least for those cases of coordination in which other kinds of pragmatic motivations are not at play). Listening to a local gustatory expert can directly affect the pleasure experienced by a person. For instance, hearing the testimony of a local gustatory expert could give someone a reason to develop

40. http://www.cbsnews.com/news/whole-foods-removes-6-asparagus-water-from-storeshelves/ 
his or her palate because it would increase the pleasure he or she gets from tasting an item. It might also put that person in touch with a new or better source of gustatory pleasure.

However, general matches might still play a role in motivating taste coordination.

Hearing the testimony of a general gustatory expert may cause us to change our beliefs about what is a good match for human beings in general. If we believe we are built similarly enough to other human beings, we may have reason to develop our palates in the manner suggested by a general expert. Of course, if a person's capacities or background diverge enough from other humans, then what makes for a good general match will not make for a good local match. However, even this sort of individual may have reason to develop his or her tastes in the manner suggested by a general gustatory expert. For instance, it may be socially or otherwise pragmatically valuable in some way, if not gustatorily valuable, to bring one's tastes in line with those of general experts. ${ }^{41}$

\subsection{The Relativity of Matches}

The second set of modifications to Railton's account concerns the relativity of matches. As we have already discussed, Railton considers matches to be relative to a species and to a genre. $4^{2}$ However, we may also want to recognize additional relativizing factors such as contextual features. Things that make for a good match in one context might not make for a good match in another context.43 I will leave open for now what sort of contextual features matter for matches while mentioning two possibilities. One is location. For example, in the context of a picnic lunch, Kool-Aid might be a reasonably good match, whereas in the context of a chic restaurant, Kool-Aid might not be as good a match. Another contextual feature is availability. In the context of a gastro pub in which there are a large number of beers on tap, Budweiser might not be a very good match. However, at a local pizza joint with only a few beers on tap, Budweiser might be a relatively good match. Much more needs to be said about relativity with regard to context, but these examples give us an idea of the role contextual factors might play in determining the goodness of matches. If it turns out that either local or general matches are relative to a variety of factors, we should require

41. Railton suggests there is a social value connected with sharing the tastes of your community.

42. See also Walton (1970) for more on the potential genre-relativity of aesthetic items.

43. If context to plays a role in determining the goodness of a match, than many of our taste disagreements may at first be meta-linguistic disagreements about which context is relevant to the evaluation of matches. This explanation fits well then, with the observations made by Sundell (2011) regarding our linguistic behavior in taste disagreements. 
that tasters, especially gustatory experts, take these factors into account when making their judgments.

\subsection{Determining the Goodness of a Match}

The final set of modifications to Railton's view concerns what determines the goodness of matches. The way I have interpreted Railton, good matches are determined by the robustness and durability of the pleasure connected to them. Robust and durable pleasures are those that become more intense the more familiar we are with an item and the more experience we have with gustatory items in general.44 In the gustatory case, it is tempting to interpret robustness and durability as meaning we would never reach a point of satiety with regard to an item. It is hard to believe there could be any items, no matter how pleasant, that we would not grow tired of if we experienced them in excess. However, this is not the way we ought to think about robustness and durability. To make things easier, we can withdraw the requirement that pleasure increase in intensity. The idea behind robustness and durability seems to be this: as time goes by, we inevitably gain more gustatory experience and, as a result, some items lose their luster as we expand our horizons. On the other hand, some items (provided we have not gone beyond the point of satiation) continue to please us, and may even please us more as time goes by. Let's call these items reliable sources of pleasure. The way I have characterized reliability it is a property of the object tasted and not of the match between the object and the individual. Reliable sources of pleasure are those that can be relied upon to yield consistent (or increasing) pleasures the more familiarity we have with that particular item and with gustatory items in general. They are sources of pleasures that are unaffected by passing fad or fancy.

\section{Resolving the Paradox of Gustatory Taste}

Earlier, I claimed offering an account of the various values that drive coordination, including gustatory value, is the key to solving the Paradox of Taste. In the following sections I will show how my account of the purposes of taste disagreements can explain both the fault and faultlessness involved in taste disagreements. This includes explaining the role of experts, evidence, retraction, and entrenchment.

44. As we have seen, Railton seemed to think that the goodness of matches was marked by how well they transcend time and culture. I will leave this issue aside for now. 


\subsection{Faultlessness Revisited}

Before I offer my solution to the paradox of gustatory taste, I would like to take a moment to clarify the notion of faultlessness in a taste disagreement. As a start, the term "fault" can be confusing as it can refer either to being in error or to being responsible for making that error (blameworthiness). As I will demonstrate shortly, either sense of fault may surface in a taste disagreement, sometimes in ways that make it difficult to differentiate between the two. Furthermore, in any sort of disagreement - taste or otherwise - a variety of errors or normative violations might be in play at any given time. For instance, in disagreements of any kind we often employ the notion of factual error. A person makes a factual error when they believe something false and a semantic error when they say something false. 45 Depending on what the norms of assertion are, an individual might be assertorically blameworthy for uttering something false. Additionally, she may have come to have the false belief and to utter a false statement because at one point she committed an epistemic error. A person could make an epistemic error by forming an epistemically unwarranted judgment-for instance by forming her belief on the basis of inadequate evidence or by disregarding evidence such as expert testimony. Depending on which epistemic norms are true, the individual might then also be epistemically blameworthy for her belief. There may even be kinds of pragmatic errors-errors one makes when one violates a relevant prudential norm (providing there are such things). Disagreements might also involve moral errors, and depending on what constitutes moral norms, individuals involved in a disagreement may be morally blameworthy for their actions, beliefs, or even their statements. ${ }^{46}$ And most importantly for our purposes, we can now add the notion of gustatory error and gustatory blameworthinessnotions that are grounded in the violation of gustatory norms. ${ }^{47}$

45. The question of when, if ever, an individual in a taste disagreement says something true or false with regard to taste claims belongs, in large part, to the semantics of taste-an issue I will put aside for now for risk of begging the question in favor of a particular semantic theory. I will leave it open whether both individuals in a taste disagreement can be faultless in the sense that neither one of them has said something false.

46. Obviously I am drastically oversimplifying both the notion of blameworthiness and the discussion of what constitutes epistemic, pragmatic, or moral blameworthiness. These issues deserve much more attention than I can give them here. My only goal here is to separate notions of fault from blame, and to suggest several ways in which individuals could be either at fault or blameworthy in a taste disagreement.

47. In order to know what it takes for an individual to fall short of her gustatory obligations, we would have to clarify the nature of gustatory norms - a project I do not have space for in this article. I suggest gustatory norms, if they exist, are conditional norms. An individual will be gustatorily blameworthy if she refuses to change her tastes in a way that would give her more or better pleasure, provided she can change her tastes and is interested in the kind of pleasure that would result from changing her tastes. In some cases an individual can be blameless for making a gusta- 
Any or all of these notions of error or blame might be involved in a taste disagreement. A person may violate an epistemic norm by unwarrantedly gathering information about what her true tastes are or should be. This may lead to a gustatory error when she fails to change her tastes in light of expert recommendation. However, in doing so she might escape making a pragmatic error if her failing to change her tastes is socially valuable in some way. ${ }^{8}$ Which notion of fault and blame is the "correct" one in taste disagreements? It depends. It is my view that context usually determines which notion of error or blame is relevant in each situation by determining the topic of conversation (though I will not argue that here). The fact the conversational topic can change the sense of fault at issue in a taste disagreement (or even whether someone is "at fault" at all), should make us question whether there really is a unified sense of "faultlessness" in play in the linguistic examples that trouble many relativists and contextualists. Nonetheless, I do believe there exists one particular kind of situation that is the main cause of the intuitions of faultlessness of the sort many relativists and contextualists feel compelled to explain. These are situations in which taste disagreements are irresolvable. I call these gustatory standoffs, which I define as follows:

Gustatory Standoffs: situations in which a taste disagreement cannot be resolved either in principle or in practice.

In disagreements that are in-principle irresolvable, there is no fact of the matter as to who is right. In these cases it is metaphysically indeterminate which of the conversational participants is in error. In other disagreements there is a fact of the matter as to who is right, but for various reasons the conversational participants cannot come to a consensus. These reasons may include stubbornness, ignorance, epistemic peerhood, and the like. ${ }^{49}$ Such disagreements, though resolvable in principle are irresolvable in practice.

As we will see, focusing on resolvability rather than faultlessness offers us a clearer route to explaining the Paradox of Gustatory taste. It is my view that by invoking the various motivations for taste coordination - including gustatory value - we can explain both resolvability and irresolvability in taste disagree-

tory error: if an individual cannot change her tastes because of limited access to culinary resources, she can't be blamed for missing out on something that would cause her pleasure.

48. As an example of pragmatic blameworthiness, it could be that drinking cheap boxed wine at a black-tie event is a social faux pas, providing one is aware of the relevant social norms. It may even be possible for someone to be morally blameworthy in a taste disagreement: if eating meat is morally wrong, then perhaps a convinced vegetarian who savors the taste of bacon is morally reprehensible.

49. If you think epistemic peerhood involves in-principle resolvability, then you might balk at the way I'm dividing it here. 
ments. Additionally, we can do this without an appeal to any particular semantic theory, as I will now demonstrate.

\subsection{Resolvable Taste Disagreement Explained}

Many substantive taste disagreements-disagreements in which the participants appeal to evidence and cite expertise-are in principle resolvable. Furthermore, many substantive taste disagreements are resolvable in practice as well..$^{\circ}$ It is because of this that retraction in taste disagreements is sometimes appropriate. Both descriptive and normative taste disagreements can be substantive. The kind of value at issue in the disagreement determines what sort of evidence is offered, who are the experts, and whether retraction is appropriate. Since gustatory value is the least familiar kind of value, I will mostly focus on showing how this sort of value can explain evidence, expertise, and retraction in the following section. And along the way, I will mention the role other kinds of value-epistemic value, for instance-can play in explaining these phenomena in taste disagreements.

\subsubsection{Evidence, Expertise, and Retraction in Descriptive}

\section{Disagreements}

Exactly who is the expert and what counts as evidence in a taste disagreement depends on the purpose of the disagreement. For instance, in a descriptive disagreement in which the goal is to discover what the speaker's tastes are at the time of the disagreement, the speaker is usually the expert. This is because it is unusual - though as Jonathan Schaffer (2011) has pointed out, not impossible, for an individual to be mistaken about what his or her tastes are at a given time. In a descriptive disagreement in which the group's tastes or the taste of the average person are at issue, we don't automatically assume that the speaker is the expert. In such cases, unless it is clear to the conversational participants which person is in the best position to determine the descriptive facts, the participants might offer evidence to determine who the expert is. Consider (20).

(20) Bar owner: I'm trying to figure out what sort of beer the average person likes so I know what to buy for the bar. What would you recommend?

Luis: Belgian Sours are tasty!

Ed: No way!

50. I say 'many' because, as I will explain in the next section, determining whether a disagreement is irresolvable can itself be a substantive debate. 
Luis: But, Ed, you love Belgian Sours-doesn't everyone?

Ed: I know I do, but the average person doesn't. I've been in the restaurant business a long time, and believe me-those sours never sell.

In other disagreements, descriptions may be relevant to a persuasive goal as in (21).

(21) Anne: What sort of pizza should we get for the party?

Matt: Anchovies are tasty!

Anne: No they aren't.

Matt: Well, I like them!

Anne: I know you do, but most people don't share your tastes.

Remember when you served escargot at the last party? Everyone hated it!

The main goal of this descriptive disagreement is pragmatic-it's to figure out what Matt and Anne should order. But, in order to do this, Matt and Anne have to determine what the average person enjoys. In this case, Anne has given Matt reason to think he is not the best judge of the average person's tastes.

\subsubsection{Evidence, expertise, and retraction in normative disagreements}

In a normative disagreement, in which the goal is to change a person's tastes, the kind of value at issue determines what counts as evidence and who counts as the expert. For instance, in an argument in which pragmatic value is at issue, evidence and expertise will be pragmatically determined. In normative disagreements where gustatory value is at issue, evidence and expertise are determined by what is really tasty.cPosition:Superscript $>51$ I have argued tastiness is a responsedependent property that is grounded in matches between human sentiment and tasty-making properties. In that case, two kinds of evidence are relevant: information about gustatory objects, in particular their tasty-making characteristics, and information about taste perspectives. The fact that evidence involving tasty-

51. With regard to gathering evidence, I have not said enough about what counts as "adequate evidence" in a taste disagreement to say when individuals in a taste disagreement are epistemically blameworthy. However, unless we set the standards for adequacy extremely low, such that an individual with no gustatory training could count as having adequate evidence, it will be possible for an individual in a taste disagreement to be epistemically at fault. On the other hand, provided we do not set the standards for adequacy too high - for instance, by requiring that an individual have an idealized level of gustatory training -it will be possible (barring any other epistemically unwarranted behavior on the part of the participants) for the participants in a taste disagreement to be epistemically faultless. 
making characteristics is relevant explains why individuals often cite properties of the object as evidence in taste disagreement. Such information may change an individual's beliefs about what is really tasty (or about what they ought to find tasty). Furthermore, it may be that noticing certain properties of the object changes the way an object tastes to someone (or perhaps merely changes an individual's awareness of her sensations). In that case, hearing evidence about tasty-making characteristics may also change a person's evaluations or preferences..$^{2}$

However, in taste disagreements individuals often cite information about subjective states instead of, or in addition to, citing information about gustatory objects. My account of gustatory value, also explains the relevance of this sort of evidence to a normative disagreement. Because tastiness depends on human sentiment as much as on properties of the object, information about an individual's taste perspective can also be relevant in taste disagreements. I will assume that, except in cases of projection or known expertise, when an individual in a taste disagreement makes a claim involving taste, she often bases her claims (at least initially) on her taste perspective at the time of utterance. If that is the case, then even if taste claims are normative, they can also convey descriptive information. When we make an utterance involving taste, we are making available to our interlocutor information about what things are like from our own taste perspectives. This can include information about what things the individual considers to be local matches. If the individual is a general gustatory expert, then knowing what things are pleasurable for her may give us information about what things are typically sources of pleasure for human beings in general. If the individual is a general gustatory expert, then we can learn which things might be sources of pleasure for individuals or for human beings in general (in some cases pending further gustatory training). Let's return to an earlier case.

(22) Undergraduate: Boone's Farm is tasty!

Wine Connoisseur: You're wrong; Boone's Farm isn't tasty. You need to branch out a bit, and you'll see what I mean.

Even though the student and the connoisseur both have good reason for their utterances at the time they make them, one of them might still have a motivating reason to change his or her taste perspective. Imagine the student thinks the

52. Although an individual may not be required to change her tastes when faced with the testimony of an established gustatory expert, she may be epistemically blameworthy for failing to change her beliefs about what makes for a good match. However, in cases in which there is no determinate expert, or in cases in which the participants cannot determine who the expert is, it may be possible for both individuals to blamelessly maintain their beliefs about what is tasty (presuming, that is, that it is acceptable to stand one's ground in cases of gustatory standoffs caused by the presence of gustatory peers). For this reason, standoff cases, which I will detail below, provide a major source for our intuitions about the faultlessness of taste disagreements. 
connoisseur is a better local gustatory expert than he is: this means the student believes he and the connoisseur are similar, but the connoisseur has a better gustatory education. The evidence offered by the connoisseur might be designed to convince the student there are better sources of gustatory pleasure than Boone's Farm. For instance, the connoisseur might think there are more reliable sources of pleasure than Boone's Farm, or sources that yield a more intense or longer lasting pleasure. It could also be that the connoisseur wants to get the student in touch with a different kind of pleasure than the pleasure provided by Boone's Farm - a more intellectual pleasure as opposed to a merely sensual pleasure. At the same time, the connoisseur's remark can serve as a way of instructing the student. If the student is interested in the kind of pleasure available to the connoisseur, he has a reason to develop his palate in the way the connoisseur suggests. If the student does manage to develop his palate, this will alter his taste perspective. When this happens, it is appropriate (though not obligatory) for the student to issue a retraction like that in (23).

(23) Undergraduate: Boone's Farm is tasty!

Wine connoisseur: You're wrong; Boone's Farm isn't tasty. You need to branch out a bit, and you'll see what I mean.

Undergraduate [post-perspectival coordination]: You're right; Boone's farm isn't tasty. [OR]

Undergraduate [post-perspectival coordination]: I was wrong; Boone's Farm isn't tasty.

In (23) we assume the student recognizes the connoisseur to be the expert because it is common knowledge that wine connoisseurs have a good deal of gustatory training. But, in many normative cases, it will not be clear to the conversational participants who the expert is. One reason to offer evidence in a disagreement about taste is to convince your interlocutor that you are a better local or general expert than she is.

You can do a variety of things to try to establish you have more gustatory expertise than your interlocutor. Provided your interlocutor has typical sensibilities, it might help to cite the fact that your tastes are shared by the majority of people, or by the majority of experts, as in (24).

(24) Josh: The food at the gas station is tasty.

Tara: No way! I have talked to a lot of people, and no one thinks the food there is tasty.

Of course, this isn't to say that such evidence is decisive. As with empirical disagreements, even the majority of people can be wrong. Another way of trying to 
establish expertise is to cite your sensitivity or gustatory training. You could also try to demonstrate your sensitivity or training by pointing out properties of the object that your interlocutor might be unaware of, for instance. In a dialogue like (25), part of what Luis seems to be doing is pointing out that his gustatory training allows him to be more sensitive to the properties of Budweiser.

(25) Ed: Budweiser is tasty.

Luis: No, Budweiser isn't tasty at all! It's so watered down, it hardly tastes like beer. Guinness, on the other hand, has a far richer flavor. If you started drinking more stouts, you would see what I mean.

Ed: No, you're wrong. You shouldn't be comparing a stout to an American lager to begin with.

It isn't always clear from the beginning whether a taste disagreement is resolvable, or what is the correct way to resolve it. The fact that matches are relative to things like context and genre will mean that often taste disagreements will be, at least in part, attempts to resolve the relativity and establish a common standard by which to judge the object. That seems to be just what Ed is attempting to do in (25) when he chides Luis for comparing a stout to an American lager. 53

\subsection{Irresolvable Taste Disagreement Explained}

If there are gustatory experts, and we have a reason to defer to these experts, then why are some disagreements irresolvable either in principle or in practice? I have tried to demonstrate several ways in which disagreements about taste can have a purpose, even if matters of taste are subjective. However, not all disagreements about taste do have a purpose. What makes some disagreements about taste worthwhile while others are pointless? Again, the answer to this question takes us back to issues pertaining to the notion of resolvability - in particular to gustatory standoffs.

\subsubsection{Ignorance and Gustatory Peers}

There are many reasons why a gustatory standoff could occur. First, the situation might involve an epistemic standoff. Epistemic standoffs in taste disagreements consist of cases in which it is difficult or impossible for the conversational participants to know whom the expert is. For instance, there may be cases of normative taste disagreements in which the conversational participants do not

53. This point about the relativity of matches seems to fit with views like Sundell (2016) which hold that taste disagreements involve meta-linguist negotiation. 
know beforehand who has more gustatory expertise and in which neither person has offered much evidence for his or her expertise. ${ }^{54}$ In this sort of situation, the standoff is often temporary. It will occur only until the two parties have more information about whom is in a better gustatory position. Except in certain cases, which I will discuss momentarily, there is some fact of the matter as to what counts as a better source of pleasure and as to who is more in touch with that source. However, because the expert may never be known, some of these cases may be irresolvable in practice. 55 In other cases, a standoff may occur because the conversational participants are gustatory peers in the sense that they are built similarly, have similar backgrounds, and have similar levels of gustatory training. Standoffs between gustatory peers are in practice and in principle irresolvable.

\subsubsection{No Determinate Expert}

Second, there are cases in which there is no determinate answer as to who is the local expert. For example, there are cases in which local matches are at issue, but the conversational participants are built very differently or have very different gustatory backgrounds, even if they have similar levels of gustatory training. If the participants are different enough from one another, neither of them can act as a local expert for the other. Failing projection, they will remain in a standoff indefinitely. A similar situation arises if we allow that there could be cases such as (26) in which two individuals have similar gustatory sensations with respect to an item but differ with regard to how much pleasure they get out of those sensations.

(26) Scotch Connoisseur 1: Macallan 21 is tasty. It's so round and smooth!

Scotch Connoisseur 2: That's false; Macallan 21 is not tasty. It may be round and smooth, but it lacks interest and character!

If the two experts are debating over general matches, then perhaps there will be a determinate expert, though they may not know who it is. However, if they are debating over local matches, then (failing projection) there will be no determinate expert. Unless the tasters have an identical physical makeup and background, it seems possible that individual differences could exist even after ex-

54. Epistemic standoffs can also occur in descriptive disagreements in which two epistemic peers discus what an individual's or group's tastes are.

55. What is the most reasonable and responsible course of action when you find yourself in a disagreement with a gustatory peer? Is there some presumption in your favor? Should you "suspend belief" that is to say, should you hold off changing your tastes? I hope to explore these questions in further work. 
tensive gustatory training. In that case, these debates will be irresolvable both in principle and in practice.

\section{7·3.3. Non-Starters}

Finally, certain dialogues about taste may appear to be irresolvable simply because they do not qualify as disagreements at all (and hence are not the sorts of things that are candidates for resolvability). "Disagreements" such as these, if we even want to call them that, are non-starters. They are not irresolvable so much as they are cases in which the individuals involved are talking past one another. While we don't want to say that all disagreements about taste are just cases of talking past, we certainly have to recognize the fact that there are some such cases.

\subsubsection{Cross-Purpose-Based-Non-Starters}

To begin with, individuals can talk past one another if they assume different conversational topics or purposes. One individual might assume the participants are involved in a descriptive disagreement, while the other might assume they are engaged in a normative disagreement. In such cases, it makes sense for an individual to retreat to a description of her own taste perspective. Entrenchment is one way of signaling the individual is assuming a descriptive aim. This is because an individual can make it clear that his or her intent was to describe his or her own taste perspective. As Schaffer's (2011) article makes clear, even if both individuals assume a descriptive aim, there might be an issue about whose tastes are being described - the speaker, the group, a contextually salient individual, and so on. Talking past can also occur in cases where both participants have normative aims but differ as to which norms they take to be relevant. For instance, one participant may have gustatory norms in mind, while the other is considering merely pragmatic norms. Furthermore, the participants in such cases of cross-purpose disagreements might be epistemically faultless if it turns out there is no right answer as to what is the conversational purpose.

In general, entrenchment can be a way of making sure the individuals in a taste disagreement are not at cross-purposes with one another. Indeed, we might extend the term 'entrenchment' to cover a variety of similar clarifications. For instance, a person could make it clear they intended to describe the tastes of a contextually salient individual, a salient group, or the average person.

Imagine that in (27), Ed and Jim are sitting in a blue-collar bar.

(27) Ed: Bud Light is tasty.

Jim: No way, it's disgusting.

Ed: Listen, I'm not saying you would like it, I'm just saying that your Average Joe does. 
Someone could even use entrenchment to mark that they are interested in a descriptive debate rather than a normative one, as in (28).

(28) Ed: Bud Light is tasty.

Jim: Are you kidding? The Beer Advocate says it's the worst beer on the market.

Ed: Listen, I'm not saying it's a great beer, I'm just saying that a lot of people like it.

\subsubsection{Match-Based Non-Starters}

Finally, the relativity of matches itself accounts for a great deal of irresolvable disagreement. If matches are relative to things such as species, genre, and context, then in some cases it will be pointless, if not impossible, to coordinate taste perspectives. For instance, if part of the point of taste disagreements is to make your interlocutor aware of general or local matches (and to allow him or her to experience a better source of pleasure), and matches are relative to genre, then it would be inappropriate to compare items from different genres, as in (29)..$^{6}$

(29) Josh: \# Candy is tastier than wine!

Tara: \# No way! Wine is tastier than candy!

Supposing that candy and wine belong to different genres, it makes no sense to compare them to see which is a better local or general match. It would be similarly pointless, though for slightly different reasons, to argue with someone or something from another species, as in (30). 57

(30) Burt the Bird: Worms are tasty!

Stan the Man: \# No way! Worms are not tasty!

If matches are relative to species, then not only is there no determinate local expert in (30), there is no determinate general expert. Of course, there might be some point to this argument initially. It is informative for us to have some evidence about what things are like from the perspective of someone of another species. This sort of information could help us to determine whether there is enough similarity to allow for a determinate local or general expert. However, it would be pointless to continue arguing after that information had been ascertained. Assuming Sam is built so differently from Burt that he could never learn

56. Although it is often inappropriate to compare items from different genres, given the right context there might be cases in which it is appropriate.

57. Again, it would be pointless unless one of the participants is reasonably able to project him or herself into the other's shoes. 
to enjoy worms, there is no reason for either one of them to try to change his mind. ${ }^{5}$

Other examples of non-starters might include cases such as (31), in which one individual is interested in what makes for good general matches while the other is interested in what makes for good local matches.

(31) Anne: What is the ideal holiday meal?

Chip: Lutefisk is tasty!

Anne: I think most people would disagree with you. After all, it's a fish packed in lye.

Chip: Sorry, I was just thinking of holidays in my family-we are Norwegian, so for us lutefisk is a treat.

It is possible that an individual is built very differently from the majority of their species so that there would be little point in disagreeing over matters of taste. In these cases, entrenchment is often appropriate.

(32) Bobby: Cupcakes are not tasty.

Lisha: Are you crazy? Everyone loves cupcakes. Of course they are tasty!

Bobby: Sorry, I just meant they aren't tasty to me-I lost my sense of taste in an accident.

One question is whether Bobby is talking about local matches or is merely describing his own experience. The answer is that an individual can speak as a local expert even if the group of those similar to them is very small. In that case, Bobby can both be describing his own tastes and taking his taste to be representative of the experiences of those like him. However, it may be possible for there to be cases in which a person is so different from the rest of her species that she has nothing in common with them. Call these "purely subjective" cases, and call the individuals involved in them "lonely local experts." On my account, lonely local experts are still technically local experts (providing they have good access to what is robustly and durably pleasurable to them). This is because they are experts in what is pleasurable to those who are like them. It is just that for these experts, no one is actually built like them.

Clearly, much more needs to be said about the way in which and the degree to which matches are relative to other factors. Furthermore, we ought to take care as we articulate the nature of relativity and its role in matches. Allowing

58. Andy Egan (2007) gives examples of cross-species disagreement, though his explanation of these examples differs from mine. 
for too much relativity can undermine our explanation of the purpose of taste disagreement. For instance, if genres are extremely specific, then it will turn out that almost every "disagreement" about taste would just be a matter of people talking past one another. For now, though, my goal is to give an explanation of the purpose of taste disagreements that can account for both fault and faultlessness. In that case I will leave the question of how best to restrict relativity for another time.

\subsection{Offering Evidence as a Way to Determine Resolvability}

So far, I've explained purposeful and pointless cases of taste disagreements by dividing them into disagreements that are either resolvable or irresolvable. But, can taste disagreements, which are irresolvable in principle, ever be substantive? In other words, do the participants in irresolvable taste disagreements ever offer evidence, appeal to experts, and so on? The answer is yes. One major reason for offering evidence in a disagreement about taste is to establish whether the disagreement is in principle resolvable. Because there are so many reasons a taste disagreement can be irresolvable, determining resolvability can itself be a substantive task. Consider, for example, a case in which the participants in a taste disagreement offer evidence to help them determine whether there is a unique local expert. To do this, they must determine whether the conditions for local expertise have been met, and this process can be difficult. For instance, the participants must discover how similarly they are built to one another, and how similar are their gustatory backgrounds. Once these preliminaries (among others) have been established, the participants can work to establish who is in a better position to detect local matches. Likewise, there may be cases in which the participants are trying to determine whether other conditions for resolvability have been met, such as the specificity of species, genre, or context.

Other examples in which individuals offer evidence to determine resolvability include cases in which it isn't clear whether both participants have the same conversational aims. For instance, one individual may have a descriptive aim while the other has a normative aim. Likewise, one person may have pragmatic norms in mind while the other is guided by gustatory norms. Similarly, one individual could be trying to establish the tastes of the group while the other is interested in the taste of a particular individual.59 In that case, even the irresolvable cases of disagreement can be substantive. Perhaps, then, the only cases that truly deserve the label "simple" are ones in which the sole purpose of the disagreement is for the participants to express their preferences, or to engage in

59. Such cases of disagreement may involve meta-linguistic disagreement as characterized by Plunkett and Sundell (2013). 
some sort of social game. Certainly such cases exist, but I think it's better to say such activities only resemble disagreements, since there is nothing that the participants are debating about.

\section{Conclusion}

I began this paper with a puzzle I called the "Paradox of Gustatory Taste." ${ }^{60}$ When we looked at some cases of taste disagreement, it seemed that the participants often failed to offer much evidence for their positions or to appeal to experts to resolve their disputes. Sometimes individuals in these taste disagreements even entrench-retreating to descriptions of their own preferences. The disputes often appeared to be faultless in some sense, and it looked as though these debates were sometimes irresolvable both in principle and in practice. With these cases, it was natural for us to suppose the subjectivity of taste, which we may have presumed precluded the possibility of error, was responsible for these features. However, when we looked at other cases, it appeared the conversational participants often did offer evidence for their positions-evidence that seemed designed to persuade their interlocutors. They frequently appealed to experts and to inter-subjective agreement to resolve their disputes, and they sometimes proceeded as if there were normative constraints on the debate. In these cases, it seemed that there was some sense in which at least one of the participants was at fault. It also appeared some of these disagreements were resolvable both in principle and in practice. I suggested that in order to explain these kinds of cases, we needed a theory of the purpose of taste disagreements - a theory that did not assume the subjectivity of taste left no room for error in these debates.

In answer, I proposed we look to the purpose (or purposes) of taste disagreements to explain the two contradictory sets of intuitions involved in the paradox of gustatory taste. I claimed there are two general types of taste disagreements: descriptive and normative. And I claimed there are a variety of reasons one could engage in taste disagreements of either kind. I argued one major motivation for taste disagreement is taste coordination. Furthermore, I claimed one key motivation for taste coordination has been overlooked - the notion of gustatory value. I went on to articulate an account of gustatory value, which utilized Railton's notion of a match. I claimed that although matters of taste are subjective

6o. The move to re-conceptualize the data generated by taste disagreements as a paradox (or puzzle) similar to Kant's aesthetic paradox itself constitutes a contribution to the debate about the semantics of taste. This is because participants in that debate often focus either on cases that seem to show taste disagreements are faultless and hopelessly subjective or (less frequently) cases in which taste disagreements seem more objective. Rarely, do writers on this issue pay attention to both. 
in the sense that they are grounded in an individual's dispositions to react or respond to gustatory items, an individual can still be mistaken about a taste judgment. Among other things, there is some fact of the matter as to what really pleases us; as to what items make for the best matches. It is possible for us to be mistaken about these sorts of facts. Since gustatory experts are in the best position to determine what items make for good matches, it makes sense for us to appeal to experts in order to resolve a dispute. If we fail to change our tastes in the way suggested by a gustatory expert, we err in the sense that we may miss out on something pleasurable. There are a number of reasons for giving evidence in a disagreement about taste. One reason to offer evidence is to persuade your interlocutor there are better sources of gustatory pleasure than the ones she currently recognizes. Another reason is to determine whether you or your interlocutor has more gustatory expertise. Yet another reason is to determine whether the disagreement is in principle resolvable: whether there is a unique gustatory expert or whether you and your interlocutor are on the same page with regard to things like genre and context. The fact some disagreements about taste are irresolvable or appear irresolvable, can be explained by the fact that in some cases either the conversational participants don't know who the expert is, or there is no determinate expert because of deep dissimilarity in the taste perspectives or taste backgrounds of the gustatory participants.

Because my theory is meta-aesthetic rather than semantic, it is neutral with regard to the semantics of taste. In principle, the theory can be paired with either relativism or contextualism - whichever view turns out to have better (independent) reasons in its favor. ${ }^{61}$ This shows the data drawn from taste disagreements (in particular, intuitions involving fault and faultlessness) does not, by itself, require us to move to complicate the semantics in the way relativists or contextualists have suggested. This does not, however, preclude the possibility that there are other sorts of arguments - syntactic arguments, for instance-that might establish the truth of either contextualism or relativism for taste predicates. Considering the prominent role disagreement data has played in the debate about the semantics of taste, this result is both surprising and significant. With the removal of taste disagreements from our list of semantic desiderata, we are free to turn to more fruitful ways of establishing the correct semantics of predicates of personal taste. Or, if we like, to spend more time gathering information relevant to taste disagreements themselves rather than the semantics of taste-a tasty option indeed.

61. I also believe my view is compatible with a minimalist, a non-cognitivist or an error theoretic sematic approach. I have simply omitted these options in order to simplify the dialectic. 


\section{References}

Bartoshuk, Linda M. and Valerie B. Duffy (2005). Chemical Senses: Taste and Smell. In Carolyn Korsmeyer (Ed.), The Taste and Culture Reader (25-34). Berg.

Beardsley, Monroe C., Michael J. Wreen, and Donald M. Callen (1982). The Aesthetic Point of View: Selected Essays. Cornell University Press.

Bowen, Richard A. (2006, December). Physiology of Taste. Retrieved from http://www. vivo.colostate.edu/hbooks/pathphys/digestion/pregastric/taste.html

Davies, Stephen (2006). Artistic Expression and the Hard Case of Pure Music. Blackwell Publishing.

Dennett, Daniel C. (1992). Quining Qualia. In A. J. Marcel and E. Bisiach (Eds.), Consciousness in Contemporary Science (3-12). Oxford University Press. https://doi.org/10.1093/ acprof:0so/9780198522379.003.0003

Egan, Andy (2007). De gustibus non disputandum est (At Least, Not Always). Manuscript submitted for publication.

Egan, Andy (2010). Disputing about Taste. In Richard Feldman and Ted A. Warfield (Eds.), Disagreement (247-286). Oxford University Press. https://doi.org/10.1093/acpr of:0so/9780199226078.003.0011

Hume, David (1875). Of the Standard of Taste. In Thomas H. Green and Thomas H. Grose (Eds.), The Philosophical Works of David Hume (Vol. 3). Longmans, Green and Co.

Kant, Immanuel (1987). Critique of Judgment. Hackett.

Kaplan, David (1989). Demonstratives. In Joseph Almog, John Perry, Howard K. Wettstein, and David Kaplan (Eds.), Themes from Kaplan (481-563). Oxford University Press.

Kölbel, Max (2004). Faultless Disagreement. Proceedings of the Aristotelian Society, 104(1), 53-73. https://doi.org/10.1111/j.0066-7373.2004.00081.x

Kölbel, Max (2008). Introduction: Motivations for Relativism. In M. Garcia-Carpintero and Max Kölbel (Eds.), Relative Truth (1-38). Oxford University Press. https://doi. org/10.1093/acprof:0so/9780199234950.003.0001

Korsmeyer, Carolyn (1999). Making Sense of Taste: Food and Philosophy. Cornell University Press.

Lasersohn, Peter (2011). Context, Relevant Parts and (Lack of) Disagreement over Taste. Philosophical Studies, 156(3), 433-439. doi:10.1007/s11098-010-9625-X

Lewis, David (1980). Index, Context, and Content. In Stig Kanger and Sven Öhman (Eds.), Philosophy and Grammar (79-100). Reidel. https://doi.org/10.1007/978-94-0099012-8_6

MacFarlane, John (2005). Making Sense of Relative Truth. Proceedings of the Aristotelian Society, 105(1), 321-339. https://doi.org/10.1111/j.1467-9264.2005.00178.x

MacFarlane, John (2007). Relativism and Disagreement. Philosophical Studies, 132(1), 1731. https://doi.org/10.1007/s11098-006-9049-9

MacFarlane, John (2011). Epistemic Modals Are Assessment-Sensitive. In Andy Egan and Brian Weatherson (Eds.), Epistemic Modality (144-178). Oxford University Press. https://doi.org/10.1093/acprof:0so/9780199591596.003.0006

MacFarlane, John (2014). Assessment Sensitivity: Relative Truth and Its Applications. Oxford University Press. https://doi.org/10.1093/acprof:0so/9780199682751.001.0001

Moltmann, Friederike (2010). Relative Truth and the First Person. Philosophical Studies, 150(2), 187-220. https://doi.org/10.1007/s11098-009-9383-9 
Nisbett, Richard and Timothy Wilson (1977). Telling More Than We Can Know: Verbal Reports on Mental Processes. Psychological Review, 84(3), 231-259. https://doi. org/10.1037/0033-295X.84.3.231

Plassmann, Hilke, John O'Doherty, Baba Shiv, and Antonio Rangel (2008). Marketing Actions Can Modulate Neural Representations of Experience Pleasantness. Proceedings of the National Academy of Sciences, 105(3), 1050-1054. https://doi.org/10.1073/ pnas.0706929105

Plunkett, David and Timothy Sundell (2013). Disagreement and the Semantics of Normative and Evaluative Terms. Philosophers' Imprint, 13(23), 1-37.

Railton, Peter (1998). Aesthetic Value, Moral Value, and the Ambitions of Naturalism. In Jerrold Levinson (Ed.), Aesthetics and Ethics: Essays at the Intersection (59-105). Cambridge University Press.

Schaffer, Jonathan (2011). Perspective in Taste Predicates and Epistemic Modals. In Andy Egan and Brian Weatherson (Eds.), Epistemic Modality (179-226). Oxford University Press. https://doi.org/10.1093/acprof:0so/9780199591596.003.0007

Schellekens, Elisabeth (2009). Taste and Objectivity: The Emergence of the Concept of the Aesthetic. Philosophy Compass, 4(5), 734-743. https://doi.org/10.1111/j.1747-9991.2009.00234.x

Scruton, Roger (2009). Beauty. Oxford University Press. https://doi.org/10.1093/actrade/9780199229758.001.0001

Stephenson, Tamina (2007). Judge Dependence, Epistemic Modals and Predicates of Personal Taste. Linguistics and Philosophy, 30(4), 487-525. https://doi.org/10.1007/s10988oo8-9023-4

Sundell, Timothy (2011). Disagreements about Taste. Philosophical Studies, 155(2), 267288. https://doi.org/10.1007/s11098-010-9572-6

Sundell, Timothy (2016). The Tasty, the Bold, and the Beautiful. Inquiry, 59(6), 793-818. https://doi.org/10.1080/0020174X.2016.1208918

Teague, Lettie (2007). Educating Peter. Scribner.

Telfer, Elizabeth (1996). Food for Thought: Philosophy and Food. Routledge. https://doi. org/10.4324/9780203002308

Walton, Kendall L. (1970). Categories of Art. Philosophical Review, 79(3), 334-367. https:// doi.org/10.2307/2183933 